\title{
Diversity, ecology and intestinal function of bifidobacteria
}

\author{
Francesca Bottacini ${ }^{1,2}$, Marco Ventura ${ }^{2}$, Douwe van Sinderen ${ }^{1}$, Mary O'Connell Motherway ${ }^{1 *}$ \\ From 11th International Symposium on Lactic Acid Bacteria \\ Egmond aan Zee, the Netherlands. 31 August - 4 September 2014
}

\begin{abstract}
The human gastrointestinal tract represents an environment which is a densely populated home for a microbiota that has evolved to positively contribute to host health. At birth the essentially sterile gastrointestinal tract (GIT) is rapidly colonized by microorganisms that originate from the mother and the surrounding environment. Within a short timeframe a microbiota establishes within the (breastfed) infant's GIT where bifidobacteria are among the dominant members, although their numerical dominance disappears following weaning. The numerous health benefits associated with bifidobacteria, and the consequent commercial relevance resulting from their incorporation into functional foods, has led to intensified research aimed at the molecular understanding of claimed probiotic attributes of this genus. In this review we provide the current status on the diversity and ecology of bifidobacteria. In addition, we will discuss the molecular mechanisms that allow this intriguing group of bacteria to colonize and persist in the GIT, so as to facilitate interaction with its host.
\end{abstract}

\section{Introduction}

Bifidobacteria are typical gut inhabitants, and represent non-motile, non-sporulating, non-gas producing, saccharolytic Gram-positive bacteria that belong to the family Bifidobacteriaceae and the phylum Actinobacteria, the latter being one of the largest and most populated taxonomic units in the domain Bacteria, and being composed of six classes and 16 orders [1]. Actinobacteria exhibit a wide spectrum of morphologies and metabolic properties, and possess genomes of a high $\mathrm{G}+\mathrm{C}$ content, ranging from $46 \%$ to over $70 \%$ (for example members of the Corynebacterium genus) [1]. Furthermore, certain representatives of this phylum produce a range of important secondary metabolites, including those that are exploited as antibiotics by the pharmaceutical industry (produced by Streptomyces spp.) [2,3].

During the last two to three decades bifidobacteria have become the subject of intensifying scientific scrutiny because they represent an abundant bacterial component of the human GIT microbiota, while they are

\footnotetext{
* Correspondence: m.oconnellmotherway@ucc.ie

${ }^{1}$ Alimentary Pharmabiotic Centre and School of Microbiology, National

University of Ireland, Cork, Western Road, Cork, Ireland

Full list of author information is available at the end of the article
}

believed to be the most dominant bacterial group present in the gut microbiota of vaginally delivered, breastfed infants [4]. They also are known to stably colonize the GIT of various other eukaryotic hosts, including mammals, birds and insects [5,6]. Their discovery has been attributed to Henri Tissier who in 1899 isolated a so-named Bacillus bifidus from breast-fed infant faeces [7]; bifidobacteria were incorrectly assigned to the genus Lactobacillus for much of the $20^{\text {th }}$ century, and only relatively recently obtained appropriate classification as a separate genus, Bifidobacterium [8].

\section{Taxonomic diversity and ecology The Bifidobacterium genus}

The Bifidobacterium genus currently comprises 48 recognized species (Table 1) [9-13]. According to taxonomic classification based on comparative analyses of 16S rRNA-encoding DNA and concatenated multilocus sequences, representing a number of conserved housekeeping genes (clpC, dnaJ, xfp, dnaB, rpoC and purF), bifidobacterial species have been clustered into six main phylogenetic clusters, consisting of the Bifidobacterium boum, Bifidobacterium asteroides, Bifidobacterium adolescentis, Bifidobacterium pullorum, Bifidobacterium 
Table 1 List of currently recognized bifidobacterial species with their isolation sources.

\begin{tabular}{|c|c|c|c|}
\hline Species & Type strain & Origin & Sequencing status \\
\hline Bifidobacterium actinocoloniiforme & DSM 22766 & Bumblebee digestive tract & - \\
\hline Bifidobacterium adolescentis & ATCC 15705 & Adult faeces & COMPLETE \\
\hline Bifidobacterium angulatum & ATCC 27535 & Adult faeces & DRAFT \\
\hline Bifidobacterium animalis subsp. animalis & ATCC 25527 & Sewage & COMPLETE \\
\hline Bifidobacterium animalis subsp. lactis & DSM 10140 & Fermented milk & COMPLETE \\
\hline Bifidobacterium asteroides & ATCC 25910 & Bee intestine & COMPLETE \\
\hline Bifidobacterium biavatii & DSM 23969 & Tamarind faeces & - \\
\hline Bifidobacterium bifidum & ATCC 29521 & Infant faeces & COMPLETE \\
\hline Bifidobacterium bohemicum & DSM 22767 & Bumblebee digestive tract & - \\
\hline Bifidobacterium bombi & DSM 19703 & Bumblebee digestive tract & - \\
\hline Bifidobacterium boum & ATCC 27917 & Bovine rumen & - \\
\hline Bifidobacterium breve & ATCC 15700 & Infant faeces & COMPLETE \\
\hline Bifidobacterium callitrichos & DSM 23973 & Marmoset faeces & - \\
\hline Bifidobacterium catenulatum & ATCC 27539 & Adult faeces & DRAFT \\
\hline Bifidobacterium choerinum & ATCC 27686 & Piglet faeces & - \\
\hline Bifidobacterium coryneforme & ATCC 25911 & Bee intestine & - \\
\hline Bifidobacterium crudilactis & LMG 23609 & Raw milk cheese & - \\
\hline Bifidobacterium cuniculi & ATCC 27916 & Rabbit faeces & - \\
\hline Bifidobacterium dentium & ATCC 27534 & Oral cavity & COMPLETE \\
\hline Bifidobacterium gallicum & ATCC 49850 & Human faeces & DRAFT \\
\hline Bifidobacterium gallinarum & ATCC 33777 & Chicken caecum & - \\
\hline Bifidobacterium indicum & ATCC 25912 & Bee intestine & - \\
\hline Bifidobacterium kashiwanohense & DSM 21854 & Infant faeces & - \\
\hline Bifidobacterium longum subsp. infantis & ATCC 15697 & Infant faeces & COMPLETE \\
\hline Bifidobacterium longum subsp. longum & ATCC 15707 & Adult faeces & COMPLETE \\
\hline Bifidobacterium longum subsp. suis & ATCC 27533 & Piglet faeces & - \\
\hline Bifidobacterium magnum & ATCC 27540 & Rabbit faeces & - \\
\hline Bifidobacterium merycicum & ATCC 49391 & Bovine rumen & - \\
\hline Bifidobacterium minimum & ATCC 27538 & Sewage & - \\
\hline Bifidobacterium mongoliense & DSM 21395 & Fermented milk & - \\
\hline Bifidobacterium moukalabense & JCM 18751 & Gorilla faeces & - \\
\hline Bifidobacterium pseudocatenulatum & ATCC 27919 & Infant faeces & DRAFT \\
\hline Bifidobacterium pseudolongum subsp. globosum & ATCC 25865 & Bovine rumen & - \\
\hline Bifidobacterium pseudolongum subsp. pseudolongum & ATCC 25526 & Pig faeces & - \\
\hline Bifidobacterium psychraerophilum & LMG 21775 & Porcine caecum & - \\
\hline Bifidobacterium pullorum & ATCC 27685 & Chicken faeces & - \\
\hline Bifidobacterium reuteri & DSM 23975 & Marmoset faeces & - \\
\hline Bifidobacterium ruminantium & ATCC 49390 & Bovine rumen & - \\
\hline Bifidobacterium saeculare & ATCC 49392 & Rabbit faeces & - \\
\hline Bifidobacterium sanguini & DSM 23967 & Tamarind faeces & - \\
\hline Bifidobacterium scardovii & DSM 13734 & Human sources & - \\
\hline Bifidobacterium stellenboschense & DSM 23968 & Tamarind faeces & - \\
\hline Bifidobacterium stercoris & JCM 15918 & Adult faeces & - \\
\hline Bifidobacterium subtile & ATCC 27537 & Sewage & - \\
\hline Bifidobacterium thermacidophilum subsp. porcinum & DSM 17755 & Piglet faeces & - \\
\hline Bifidobacterium thermacidophilum subsp. thermoacidophilum & DSM 15837 & Anaerobic digester & - \\
\hline Bifidobacterium thermophilum & ATCC 25525 & Piglet faeces & COMPLETE \\
\hline Bifidobacterium tsurumiense & JCM 13495 & Hamster dental plaque & - \\
\hline
\end{tabular}


longum, and Bifidobacterium pseudolongum phylogenetic groups, where Bifidobacterium asteroides, isolated from the insect gut, appears to be the closest relative of the ancient progenitor of the genus Bifidobacterium [9].

Several of the currently recognized species have only very recently been isolated, such as Bifidobacterium actinocoloniiforme, Bifidobacterium bohemicum, Bifidobacterium bombi, Bifidobacterium biavatii, Bifidobacterium reuteri, Bifidobacterium callitrichos, Bifidobacterium sanguini, Bifidobacterium stellenboschense, Bifidobacterium stercoris, Bifidobacterium kashiwanohense and Bifidobacterium moukalabense [10-13]. Interestingly, as shown in the 16S rDNA-sequence-based Neighbourjoining tree in Figure 1, three additional phylogenetic clusters seem to be present in Bifidobacterium, representing the B. crudilactis, B. bohemicum and B. scardovii groups. Moreover, microbiota analysis by $16 \mathrm{~S}$ rRNAencoding DNA sequences has indicated that more bifidobacterial species are yet to be discovered $[4,14]$, and for this reason we may expect further expansion or refinement of this classification.

Bifidobacteria have been isolated from a variety of ecological niches, such as sewage, fermented milk and anaerobic digestion facilities, yet are most frequently associated with the GIT of humans and animals (in general where the offspring of the bifidobacterial host is raised with parental care which may ensure direct transmission from mother to child/progeny) [15-17].

Their ecological adaptation may also differ among species, some of them for instance can be present in different niches, such as in the case of Bifidobacterium adolescentis, Bifidobacterium animalis, Bifidobacterium dentium and Bifidobacterium catenulatum (referred to as cosmopolitan bifidobacterial taxa), while others appear to be much more niche-specific, for example Bifidobacterium cuniculi, Bifidobacterium angulatum and Bifidobacterium gallinarum (so-called specialized bifidobacterial taxa) [18].

\section{General genome features}

Bifidobacterial chromosomes have a genome that ranges in size between 1.9 and $2.8 \mathrm{Mbp}$, with representatives of the $B$. animalis species possessing the smallest genome, and a representative of $B$. longum subsp. infantis harbouring the largest reported genome (Table 2). Bifidobacterial genomes are predicted to encode a substantial number of tRNA molecules, which averages at 52 tRNAencoding genes per genome, with an outlier in the case of the B. longum subsp. infantis ATCC 15697 genome, which contains a reported 79 tRNA-encoding genes [19] (Table 2). Interestingly, despite the fact that bifidobacteria possess a tRNA-encoding gene for all common amino acids, genes encoding the amino acyl-tRNA synthetases for glutamine and asparagine are absent in bifidobacteria, and the corresponding charged tRNAs are believed to be produced with the involvement of specific Asn- and Gln-tRNA amidotransferases, performing transamidation of misacetylated Asp-tRNA(Asn) and Glu-tRNA(Gln) [20,21]. The organization of the bifidobacterial chromosome also appears to be consistent with that of a typical bacterial genome, showing a set of conserved genes around the predicted origin of replication (including $r p m H, d n a A$, dnaN and $r e c F$ ) and a region rich in AT and multiple DnaA-binding boxes in proximity of the gene specifying the presumed chromosomal initiator of replication $(d n a A)$ [22]. Finally, a switch in the direction of the $\mathrm{GC}$ skew [the $(\mathrm{G}-\mathrm{C}) /(\mathrm{G}+\mathrm{C})$ value] is observed in bifidobacteria at the origin and terminus of replication, so that the leading strand tends to be higher in Guanine content as compared to its Cytosine content $[1,23]$. The copy number of rRNA-specifying loci represents another variability in bifidobacterial genomes, and ranges between two and five (Table 2).

In silico gene predictions show that representatives of the Bifidobacterium genus contain an average of 2012 open reading frames (ORFs) per genome, where genomes of $B$. animalis subsp. lactis and B. longum subsp. infantis possess the smallest and largest number of ORFs, respectively, being consistent with their genome size. It is also possible that the lower number of genes observed in $B$. animalis subsp. lactis genomes have been caused by their wide-spread utilization in commercial preparations, leading to phenomena of gene loss and genome decay as a result of the adaptation to a nutrient-rich environment, being in agreement with what was also observed in certain lactic acid bacteria [24-26].

\section{Comparative genomics of bifidobacteria}

Comparative genomic analysis of the genus Bifidobacterium involving genome sequences of nine bifidobacterial species, $B$. longum subsp. longum, $B$. longum subsp. infantis, $B$. adolescentis, $B$. dentium, $B$. bifidum, B. animalis subsp. lactis, B. angulatum, B. catenulatum and B. gallicum and full nucleotide sequence alignment revealed that these genomes are not colinear, showing a frequent interruption of chromosomal synteny, thereby inferring the existence of significant genome diversity within members of the genus Bifidobacterium caused by chromosomal rearrangment events. The Bifidobacterium core genome was determined to consist of 506 orthologues that are shared by all nine bifidobacterial species. Functional annotation established that these core genes primarily encode housekeeping functions, including those dedicated to replication, transcription and translation, as well as genes associated with adaptation to a particular niche environment, e.g. genes associated with carbohydrate metabolism, signal transduction and cell envelope biogenesis [27]. The number of truly unique genes (present in a single 


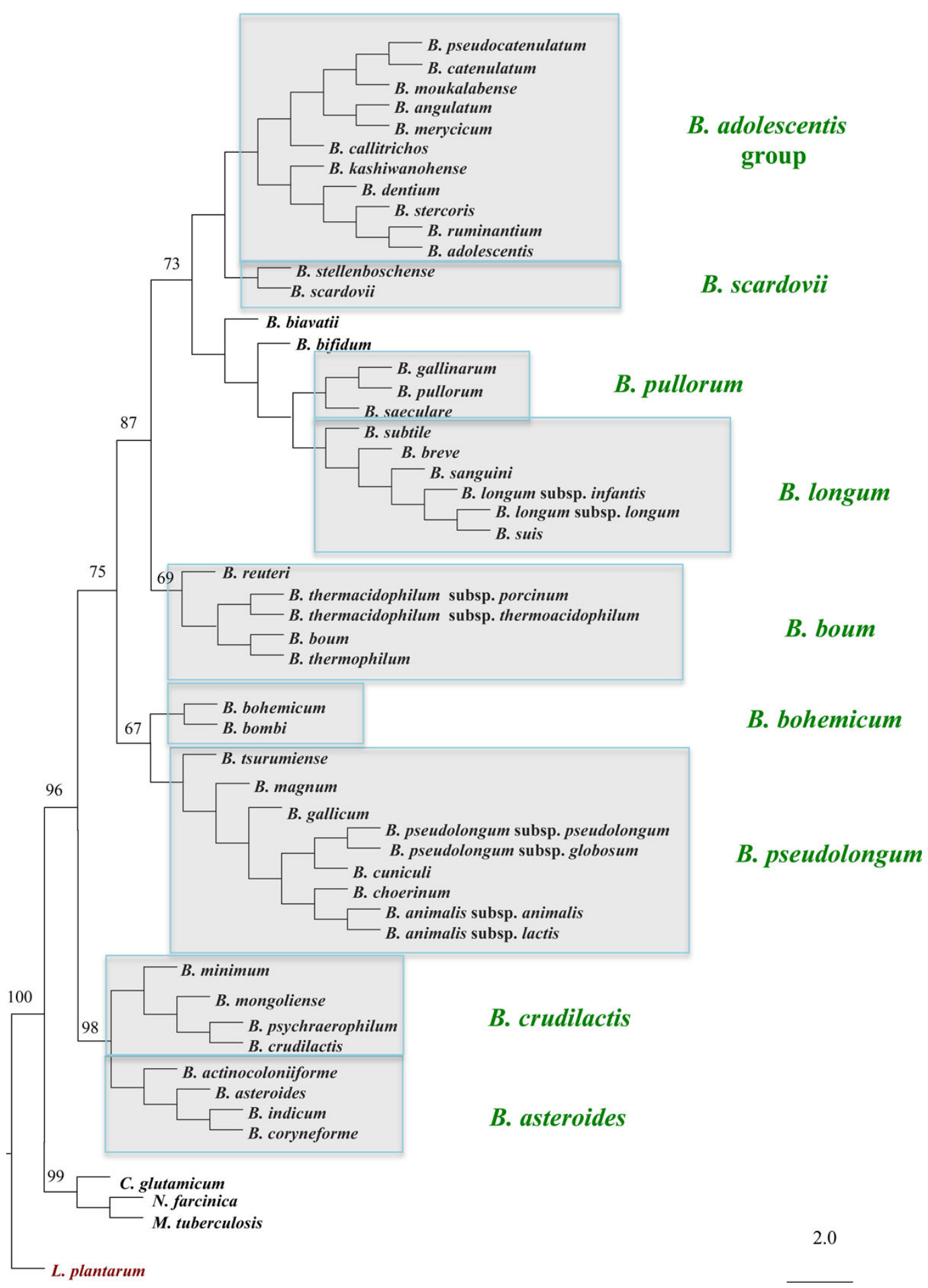

Figure 1 Rooted neighbour-joining tree based on the alignment (1265 nucleotides) of the 16S rRNA gene (96\% of homology) sequence from the 48 so far recognized bifidobacterial taxa (Dec., 2013). The phylogenetic groups, as highlighted in grey shaded

quadrangles, are the result of a previously performed multilocus analysis [9], integrated with the information resulting from the alignment of the 165 sequence of new bifidobacterial species. 


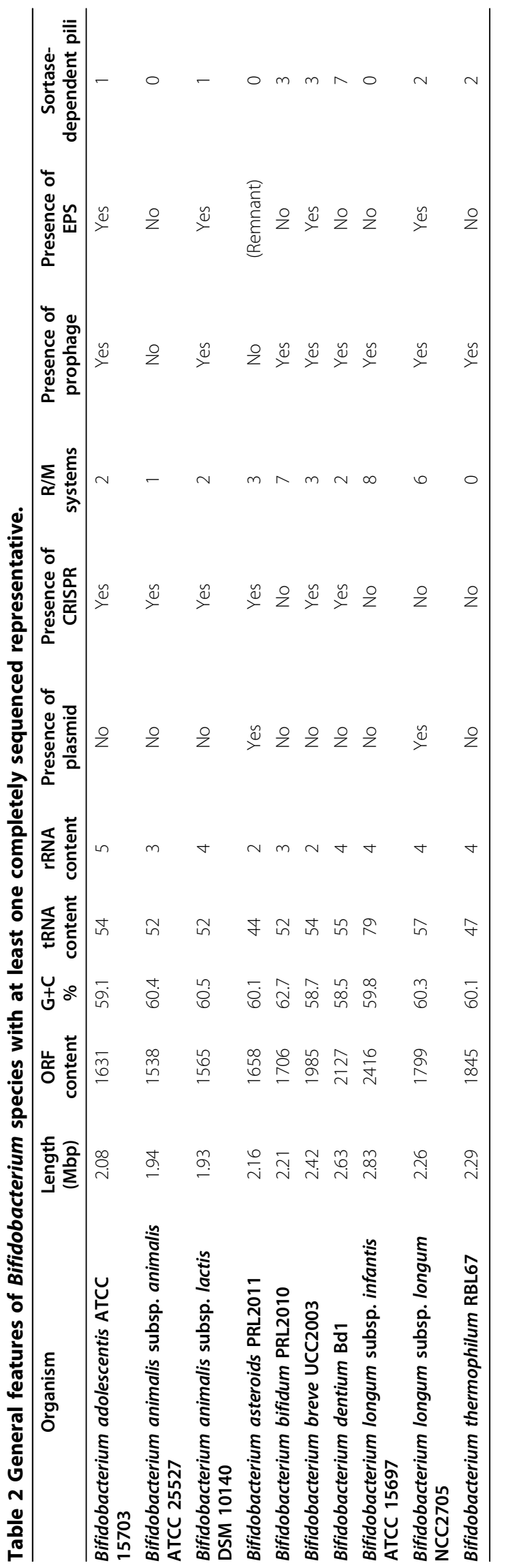


reference genome but absent in all other analysed genomes), varies between 21 and 230 genes in the nine genomes analysed. The majority of such unique genes have no functional annotation, thereby suggesting that these genes encode for novel biosynthetic or bifidobacterial-host interaction molecules.

Our recent analysis of the pan-genome of the $B$. breve taxon, adopting complete genome sequences of eight $B$. breve strains, namely $B$. breve UCC2003, B. breve NCFB 2258, B. breve ATCC 20213, B. breve JCM 7017, B. breve JCM 7019, B. breve ACS-071-V-Sch8b, B. breve 12L, $B$. breve $\mathrm{S} 27$ established that these genomes are highly syntenic, with the exception of $B$. breve ACS-071-V-Sch8b and $B$. breve JCM 7017 that harbour inversions in their genomes of $1.1 \mathrm{Mb}$ and $126 \mathrm{~Kb}$, respectively. Analysis of the core and dispensable genome highlighted that the $B$. breve coregenome is comprised of 1,323 core gene families and as expected these encode functions dedicated to cellular housekeeping. From the eight $B$. breve genomes 924 families of variable genes were identified and of these 426 could be classified as truly unique genes. The variable genes encoded proteins involved in capsular polysaccharide biosynthesis, phage resistance (restriction-modification systems and CRISPR loci), production of sortase dependent pili, and carbohydrate transport and utilisation. An extension of the pangenome analysis to include genomes of 6 publically available B. longum subsp. longum sequences established that 564 gene families were uniquely present in B. breve and absent in B. longum subsp. longum, and while $50 \%$ of these encoded hypothetical functions the other $50 \%$ were found to encode $B$. breve specific glycosyl hydrolases, $\mathrm{ABC}$ transporters, CRISPR genes and mobile elements [28].

\section{Mobilome}

The pool of mobile elements so far found in bifidobacteria is represented by insertion sequences, prophage-like elements and plasmids [29,30]. Regarding insertion sequences, representatives of the main families that have been reported to be present in bifidobacterial genomes are IS3, IS21, IS30, IS110, IS150, IS256, IS607/200 and ISL3, where in general representatives of IS30 appear to be the most abundant and active in bifidobacteria. In fact, it has been suggested that IS 30 is active in B. longum subsp. longum and involved in causing genome deletions and rearrangements, supporting the suggested role of IS elements in environmental adaptation of bifidobacteria in general [29].

In contrast to what was initially thought, bifidobacteria appear to be subject to phage infections [30]. Sgorbati et al [31] assessed fourteen strains of B. longum by UV and mitomycin $C$ induction for the release of prophage. Bacteriophage were identified from four of the $B$. longum cultures, with the phage head diameters ranging from
49-56 $\mathrm{nm}$ while their tails ranged in length from $76-268 \mathrm{~nm}$. In fact, the presence of one or more prophagelike elements has been observed in several bifidobacterial genomes (Table 2) [32]. The notion that prophage-like elements may act as a transmission vehicle of genes that do not appear to be essential for phage functions (e.g., hypothetical proteins and glycosyl hydrolase enzymes) is evidence for their potential involvement in lateral gene transfer, and the acquisition of such elements may result in an enhancement of ecological fitness in the receiving members populating the same ecologica niche [33]. Interestingly, bifidobacterial prophage insertion has in several cases been shown to occur at a 35-bp sequence located at the end of the gene specifying tRNA ${ }^{\text {Met }}$ [30]. Moreover, an evolutionary analysis conducted on suspected bifidobacterial prophage sequences revealed in a number of cases a high level of sequence identity with prophages present in high and low $\mathrm{G}+\mathrm{C}$ content Gram-positive bacteria, supporting the hypothesis of phage-mediated DNA exchange between Actinobacteria and Firmicutes, perhaps facilitated by the fact that these bacteria in certain cases share a common niche [32].

The majority of bifidobacterial strains do not harbour any plasmid and, if they do, a given isolate rarely contains more than one such extrachromosomal genetic element, which then range in size from 1.5-15 Kb. So far, B. longum subsp. longum and B. breve represent the species with the highest number of strains in which plasmids have been identified, with 18 reported plasmidharbouring representatives of $B$. longum subsp. longum and three of B. breve [29]. Analysis of their replication (Rep) proteins has indicated that the majority of identified bifidobacterial plasmids replicate by means of the so-called rolling circle mechanism (RCR), while other functions, if encoded, still remain to a large degree unknown [29].

\section{CRISPR loci and restriction modification systems}

As mentioned above, bifidobacteria were until relatively recently not thought to be prone to phage infections since their was no evidence of infection, however, genome analysis of several bifidobacterial strains revealed the presence of predicted phage resistance systems, in particular CRISPR and restriction modification (R-M) systems. The former anti-phage system was not only found in $B$. animalis subsp. lactis, but also in one or more representatives of $B$. animalis subsp. animalis, $B$. longum subsp. longum, $B$. breve, $B$. bifidum, $B$. dentium, $B$. adolescentis, $B$. asteroides, $B$. angulatum and B. catenulatum species [21,29].

Restriction/modification (R-M) systems are ubiquitous among prokaryotes and generally comprise of a restriction endonuclease (REase) and cognate methyltransferase (MTase) [34]. R-M systems serve primarily as defensive instruments that protect prokaryotic cells 
against invading DNA such as promiscuous plasmids or infecting bacteriophage as the unmodified incoming DNA is targeted by the REase component of the R-M. The host DNA is resistant to cleavage as the recognition sites of the endonuclease are modified by the cognate methyltransferase at adenosyl or cytosyl residues. R-M systems are classified into four groups (designated type I, II, III and IV) on the basis of their subunit composition, co-factor requirement, recognition sequence structure and the cleavage site relative to the recognition sequence [35]. REase activity in Bifidobacterium was first described by Khosaka et al. [36,37], who identified the restriction endonucleases BbeI from $B$. breve YIT4006, and BinSI and BinSII from B. longum subsp. infantis S76e. Subsequently, REase activity was demonstrated in strains of $B$. adolescentis, B. bifidum, B. lactentis (subsequently reclassified as $B$. longum subsp. infantis) and B. longum subsp. longum [38-40]. In silico analysis of sequenced bifidobacterial genomes shows that the number of R-M systems varies not only between bifidobacterial species, but also between strains of a particular species (Table 2). The genome of $B$. thermophilum lacks $\mathrm{R}-\mathrm{M}$ systems, while strains of $B$. bifidum harbour the genetic determinants to encode between four and seven $\mathrm{R}-\mathrm{M}$ systems and genes encoding up to eight R-M systems have been identified on the sequenced genomes of strains of $B$. longum subsp. infantis. The ability to circumvent the R-M complement of strains of $B$. longum and $B$. adolescentis has allowed with the introduction of E. coli-bifidobacterial shuttle vectors into these strains by electroporation $[41,42]$, while for $B$. breve strains it has allowed the creation of insertion mutants via site specific homologous recombination or transposon mutagenesis [43], thereby advancing our understanding of bifidobacterial genomics, physiology and metabolism $[28,44,45]$.

\section{Evidence of horizontal gene transfer}

Bacterial genome evolution occurs through various mechanisms, which include gene duplication, chromosomal rearrangements, vertical DNA exchange and intraspecies horizontal gene transfer (HGT), events that may facilitate rapid environmental adaptation [46]. For this reason, defining the precise evolutionary distance between bacterial taxa is a complex and difficult task, and the presence of a common ancestor may not be sufficient in measuring the true distance between two phylogenetic groups, when also taking the presence of common functions for genetic adaptation to a common niche into account.

HGT appears to play an important role in increasing the competitiveness of bacteria in their ecological niche, and in bifidobacteria DNA regions acquired through HGT are frequently present in clusters that are randomly dispersed across the genome and in many cases being flanked by mobile elements $[21,47,48]$.

\section{Intestinal function}

\section{Adaptation to the gastrointestinal environment}

In order to survive gastrointestinal transit and transiently colonise the GIT, bifidobacteria must be able to counter the adverse conditions of the oral cavity, stomach and small intestine. In particular, exposure to oxygen or other oxygen-derived free radicals, organic acids, and bile, as well as osmotic stress can have a negative impact on bifidobacterial cell viability and consequently probiotic functionality. Bifidobacteria cope with these stressful conditions by adopting a repertoire of molecular chaperones, bile efflux transporters, bile salt hydrolases, twocomponent systems and ATPases [49-55]. Tight control of these stress-induced coping mechanisms allows bifidobacteria to rapidly react to various and sometimes complex environmental challenges. This regulation is governed by an interactive nextwork of regulators that include ClgR, HspR, HrcA, and LexA. The regulons are highly conserved among sequenced bifidobacterial genomes suggesting that a universal system for adaptation to osmotic, oxidative and acid stress exists among all members of the Bifidobacterium genus [55]. Bile tolerance is among the most crucial properties for a probiotic bacterium as it determines a strain's ability to survive transit through the small intestine. The active extrusion of bile acids and salts that accumulate in the cytoplasm through efflux pumps is a commom mechanism employed by bacteria to counter bile toxicity. Multidrug transporters belonging to the ATP-binding cassette or major facilitator family have been described as mediating bile tolerance in strains of $B$. longum subsp. longum and B. breve UCC2003 [49,56,57]. In B. breve UCC2003 Bbr_0838 encoding a multidrug transporter of the major facilitator family is strongly induced during exposure to bile. Inactivation of Bbr_0838 through insertional mutagenesis rendered the mutant strain, UCC2003-838, more sensitive to cholic acid compared to the parent strain demonstrating that cholate is the main bile component detoxified by Bbr_0838 [49]. Survival in the highly complex and competitive environment of the GIT requires that commensal bacteria including bifidobacteria can protect themselves against host proteases. Some bifidobacterial species achieve protection against human proteases, such as $\alpha$ antitrypsin and human neutrophil elastase, by a serine protease inhibitor (Serpin), the production of which is regulated by an environmental sensing two component regulatory system $[51,53]$.

\section{Interaction with the host environment}

The mechanisms by which bifidobacteria interact within the gut environment and adhere to the host surfaces are still under investigation and the recent availability of several bifidobacterial genome sequences underlined the presence of a number of macromolecules associated 
with the cellular envelope and involved in host-microbe interactions $[48,58,59]$. The capsular or surface exopolysaccharide (sEPS) is one such macromolecule which was shown to contribute to host colonization and persistence by facilitating bifidobacterial long-term colonization of host cells $[1,60,61]$. Another extracellular structure which is crucial in the process of colonization of the intestinal mucosa is represented by appendices called fimbriae or pili, found in both enteric and oral bifidobacteria [21,62-64]. They can be involved in the establishment of host cell contact and adhesion to the epithelial cells, in cellular aggregation or in biofilm formation, but they may also stimulate a response by the host immune system [48,59]. Bifidobacteria have long been recognized for their ability to prevent pathogen infection, however, the precise mechanism has remained elusive. Recent research has demonstrated that gut pathogen protection conferred by bifidobacteria is associated with LuxS and AI-2 production via a mechanism that may be correlated with iron acquisition (Christiaen et al., submitted).

\section{Exopolysaccharide production}

A bacterial sEPS usually consists of a complex extracellular structure composed of a repetition of mono/oligosaccharides linked through glycosidic bonds, which determines the properties of the homo/heteropolymeric structure. The bacterial sEPS was first studied and characterized in pathogens, where such macromolecules play a crucial role as a virulence factor in the interaction of the bacterium with its host through modulation of the immune system [65].

Differently from pathogens, the sEPS in commensal bacteria (such as bifidobacteria) has only recently received scientific attention and very little is known about its precise biological role. The involvement of sEPS in providing tolerance to bile salts and low $\mathrm{pH}$ has previously been eluded to [66], while a recent study conducted in B. breve UCC2003 demonstrated that its surface-located EPS promotes in vivo persistence by mediating evasion of the $B$ cell-mediated adaptive immune response in the murine gut and preventing the production of proinflammatory cytokines such as IFN $-\gamma$, TNF- $\alpha$ and IL-12 [67].

The genome of $B$. breve UCC2003 contains two predicted EPS-encoding gene clusters: eps1, elements of which are similar to a cluster involved in the formation of a cell wall-associated phospho-polysaccharide or pellicle in L. lactis subsp. cremoris MG1363 [68] and eps2, which is responsible for sEPS production.

Interestingly, the eps 2 locus is organized in two adjacent and oppositely oriented operons (called eps $2 A$ and eps $2 B$, Figure 2), one of which is constitutively transcribed, while the other is transcriptionally silent unless a promoter reorientation reverses this situation using a mechanism that is likely to be similar to that observed in Bacteroides fragilis $[67,69]$. More specifically, this promoter inversion is presumed to be catalyzed by the presence of an inverted repeat sequence in the intergenic region between eps $2 A$ and eps $2 B$, and the activity of an as yet unidentified site-specific DNA invertase/recombinase [67]. Recent comparitive analysis on eight fully sequenced $B$. breve genomes revealed the presence of an intact eps 2 locus in B. breve JCM 7017, B. breve JCM $7019, B$. breve $689 \mathrm{~b}$ and $B$. breve S27, while the genomes of $B$. breve ACS-071-V-Sch8b, B. breve NCFB 2258 and B. breve $12 \mathrm{~L}$ appear to contain only a remnant EPS cluster, where the gene encoding the priming glycosyl transferase is present, yet lacking several genes commonly associated with EPS biosynthesis [28]. Aside from B. breve, putative EPS-specifying regions are also present in the genomes of most other bifidobacterial species, for example a complete locus has been identified in members of $B$. animalis subsp. lactis, B. longum subsp. longum and B. pseudocatenulatum $[61,68,70]$ (Table 2). Interestingly, the $\mathrm{G}+\mathrm{C}$ content of these regions deviates from that of the genome and suggests their acquisition through a HGT mechanism [48]. Further functional analyses are needed to determine the structural diversity of bifidobacterial EPS polymers and their associated biological function.

\section{Pili in bifidobacteria}

The mechanism of interaction between gut microbes and the intestinal mucosa may involve hair-like appendices, named pili or fimbriae, which are exposed on and attached to the cellular surface. Apart from the process of host colonization, pili may also be involved in other cellular functions, which include protein secretion and conjugation [71].

During colonization bifidobacteria are believed to establish an initial contact with the host surface, followed by a more tight and specific adhesion [48]. Two different types of pili are held responsible for this process: the type IVb or so-called tight adherence pili (Tad pili) and the sortase-dependent pili. Both of these extracellular structures are composed of assembled pilin subunits where in the case of Tad pili they are linked by non-covalent interactions and attached to the membrane lipid bilayer, while in the case of sortase-dependent pili they are covalently anchored to the cell wall and their subunit assembly involves the establishment of covalent bonds catalyzed by a dedicated transpeptidase enzyme (so-called sortase) [72].

Tad pili were first characterized in the Gram-negative coccobacillus Actinobacillus actinomycetemcomitans, where they are shown to be required for adhesion to host surfaces, colonization and pathogenesis [73,74]. 


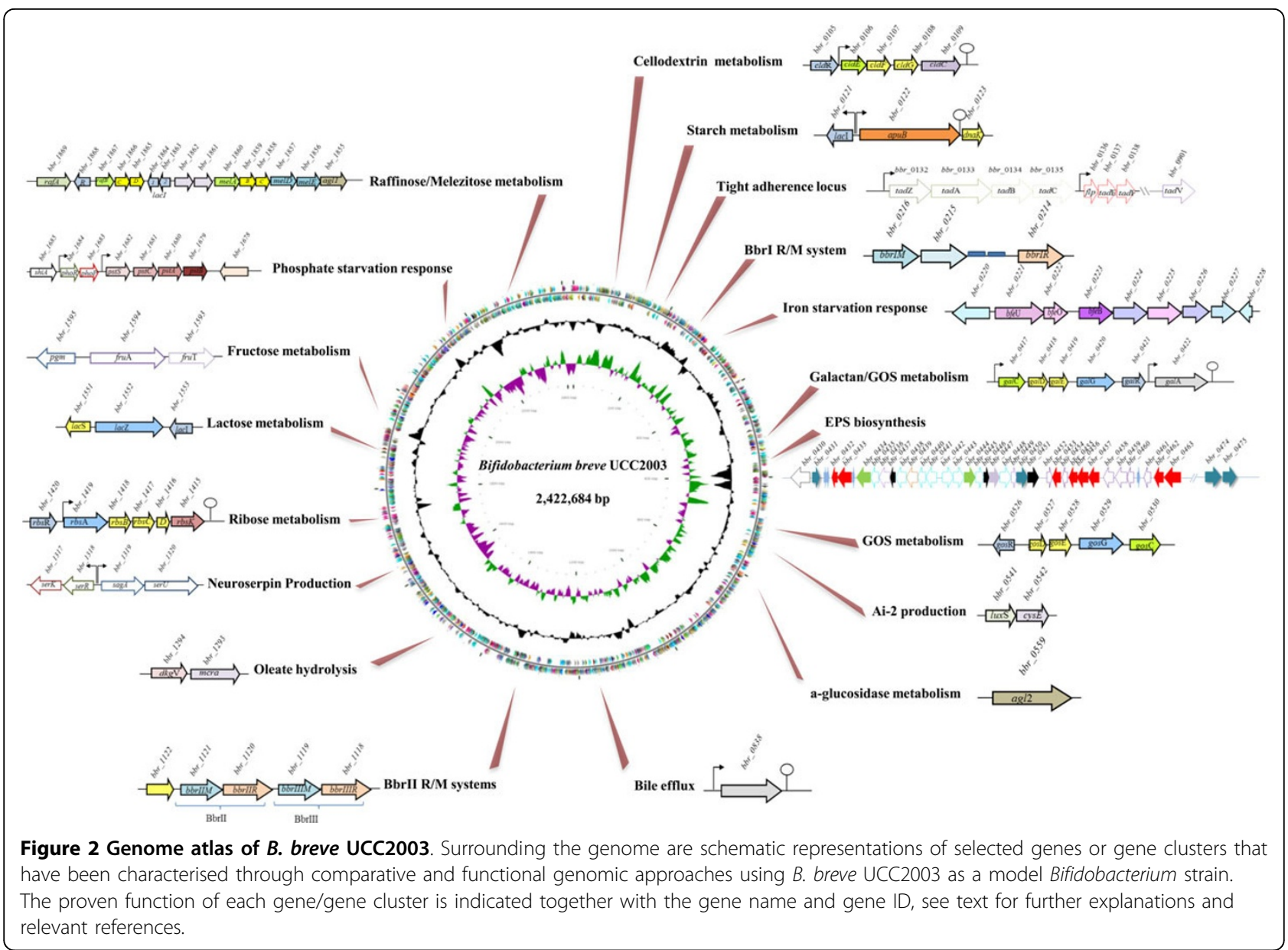

The assembly apparatus is composed of an ATPase (TadA) associated with two membrane proteins (TadB and $\mathrm{TadC}$ ), together constituting the secretion system, a septum site-determining protein (TadZ), which directs the pilus secretion machinery to a cell-polar position, and finally a peptidase (TadV), which cleaves a leader peptide from the prepilin precursors [75]. This locus is present in both Bacteria and Archea, and is for this reason termed a Widespread Colonization Island (WCI) because of its common presence among and apparent mobility between phylogenetically distant micro-organisms [76]. Highly homologous Tad pili-encoding genes are present in all currently sequenced bifidobacterial genomes, which enforces their presumed role in the establishment of a direct interaction with their host. A recent description of the genome sequence of $B$. breve UCC2003, together with an in vivo transcriptomic and mutational analysis, confirmed the involvement of Tad pili in murine gut colonization by $B$. breve [48].

In contrast, sortase-dependent pili have been observed decorating the bifidobacterial cell surface and their expression seems to be strongly dependent on growth conditions
[64]. One or more sortase-dependent pilus-encoding loci are present in the genome of most, but not all, bifidobacterial species (Table 2), where $B$. dentium represents the bifidobacterial species with the highest number of pilusencoding loci (Table 2) [21]. A typical sortase-dependent pilus-specifying locus in a bifidobacterial genome consists of a gene cluster composed of one or two pilus subunitencoding genes with a dedicated sortase-encoding gene placed in an adjacent position [64].

Various sortase-dependent pilus-specifying clusters found in other bacteria are thought to have been acquired through lateral transfer due to their deviating $(\mathrm{G}+\mathrm{C})$ content, and a phylogenetic analysis conducted on bifidobacterial gene clusters predicted to be involved in the biosynthesis of sortase-dependent pilus-like structures was shown to be consistent with this notion [71].

Notably, a recent study conducted on B. bifidum PRL2010 established an additional function of sortasedependent pili as they were not only shown to be involved in the specific binding to extracellular matrix components (in this case fibronectin and collagen), but were also shown to be responsible for bacterial aggregation [59]. 
Perhaps this aggregation phenotype may allow individual cells of this gut commensal to adhere to each other in order to enhance the colonization of the host mucosa, using a mechanism similar to the one described for the probiotic strain Lactobacillus rhamnosus GG [77,78]. Moreover, this study demonstrated that such pili play a role in modulating the host immune response, on the one hand inducing a high level of expression of TNF- $\alpha$ cytokines known to be produced at local level as a result of inflammatory disease, while on the other hand acting as low-level inducers of other proinflammatory cytokines (e. g., IL-12), associated with systemic responses [59]. Furthermore, the induction of TNF- $\alpha$ exerted by pili of PRL2010 cells may be crucial for the initiation of crosstalk among immune cells without causing any inflammation or detrimental effects [79]. In fact, the infant's immune system is immature and the presence of proinflammatory stimuli such as those provoked by pili of $B$. bifidum PRL2010 may be essential to achieve appropriate developmental immunological programming [59].

\section{Al-2 production by bifidobacteria}

A wide range of Gram-negative and Gram-positive bacterial species produce the quorum sensing molecule AI-2 and for this reason it is often referred to as the interspecies signaling molecule. The key enzyme for AI-2 production is LuxS, which is an essential part of the activated methyl cycle, involved in recycling S-adenosylhomocysteine. More specifically, LuxS catalyzes the cleavage of S-ribosyl-homocysteine to homocysteine and 4,5-dihydroxy-2,3-pentanedione (DPD), which subsequently leads to the production of AI-2 [80]. Although AI-2 is commonly linked to virulence and pathogenicity $[81,82]$, it has recently been shown that probiotic Lactobacillus strains, including Lactobacillus acidophilus NCFM, Lactobacillus rhamnosus GG and Lactobacillus reuteri, each harbour a functional $l u x S$ gene and produce AI-2 [83-86]. We recently established that all Bifidobacterium strains sequenced to date harbor a luxS gene, and our investigations have demonstrated that all tested bifidobacterial strains, representing 11 species of this genus, were capable of producing AI-2. Through insertional inactivation and subsequent complementation experiments we demonstrated that a functional lux $\mathrm{S}$ gene is necessary for bifidobacterial AI-2 production. In addition, we observed downregulation of genes associated with iron transport in a luxS insertion mutant strain, UCC2003-luxS, during in vitro growth. Consistent with this result UCC2003-luxS was shown to be more sensitive to various iron chelators, and unable to colonize the murine gastrointestinal tract, while this mutant also conferred less protection against Salmonella infection in a C. elegans nematode model. Collectively these data demonstrate the importance of LuxS for bifidobacteria to establish as gut commensals, which also includes their beneficial effect pertaining to pathogen protection/exclusion [87]. Furthermore, our results indicate that LuxS activity is involved in iron acquisition, a property that gives B. breve UCC2003 a competitive advantage in iron-limited environments such as the gastrointestinal tract.

\section{Production of bioactive metabolites}

Metabolic end products, such as SCFA, vitamins, polyunsaturated fatty acids such as conjugated linoleic acid also contribute to intestinal functionality and probiotic attributes of bifidobacteria. SCFAs are the end products of bifidobacterial fermentation of complex carbohydrates in the GIT, and have been found to be key for human metabolism as they stimulate water and sodium absorption, lower luminal $\mathrm{pH}$ and the bioavailability of toxic amines [88]. Recently, it was shown that acetate produced by bifidobacteria could enhance intestinal defence mediated by epithelial cells and thereby protecting the host against infection by E. coli O157:H7 [89]. In addition, while bifidobacteria do not produce butyrate as an end product of fermentation, de Vuyst and Leroy have demonstrated the importance of cross-feeding on acetate by butyrate-producing bacteria in the gut [90]. Butyrate is the primary energy source for colonocytes and has attracted much research interest due to the possibility of its use for the prevention of colon cancer [91]. Conjugated linoleic acid (CLA) refers to a mixture of positional and geometric isomers of the essential fatty acid linoleic acid (C18:2, cis-9, cis-12 octadecadienoic acid). CLA has been reported to be produced by some human bacterial isolates from different bacterial groups that include Lactobacillus, Propionibacterium, Bifidobacterium, Pediococcus, Enterococcus and Lactococcus. Among bifidobacteria, strains of $B$. breve have been show to produce high levels of CLA [92]. CLA has been shown to exert several health benefits and has been demonstrated to have potent anti-inflammatory, immunomodulatory, anti-obese and anti-carcinogenic activity, along with the ability to improve biomarkers of cardio-vascular health [93].

\section{Carbohydrate transport and metabolism by bifidobacteria} One way by which gut commensals exert their beneficial effect on their hosts is by degrading diet-derived carbohydrates that cannot be digested by host enzymes, such as plant-derived glycans (e.g., glucans, fructans, xylans, resistant starch, pectins, cellulose, arabinoxylan, and their respective oligosaccharide degradation products), and host glycans (e.g., Human Milk Oligosaccharides or HMO, and mucin-type $\mathrm{O}$-and $\mathrm{N}$-glycans).

Of such carbohydrates, bifidobacteria can degrade certain polysaccharides by extracellular enzymes into monoand/or oligosaccharides, which are then internalized using 
mostly sugar-specific ATP-binding cassette (ABC) transporters, permeases, proton symporters and, in a few cases, phosphoenolpyruvate-phosphotransferase (PEP-PTS) systems $[21,94]$. Once internalized in the cytoplasm, carbohydrates may be subjected to further hydrolysis, epimerization, deacetylation, deamination and/or phosphorylation involving the participation of specific enzymes, such as glycosyl hydrolases, sugar phosphorylases, epimerases, mutases and/or kinases [94].

All necessary genes involved in the utilization of a given sugar are frequently organized in gene clusters containing genes that encode one or more specific glycosyl hydrolases and transport systems, and are usually placed under the transcriptional control of a LacI-type regulator specified by a gene that is also located adjacent to or within such a gene cluster [62].

The fermentation pathway of simple and complex carbohydrates employed by bifidobacteria converges to a specific metabolic route called "bifid shunt" which yields 2.5 ATP molecules per $1 \mathrm{Mol}$ of glucose, $1.5 \mathrm{Mol}$ of acetate and $1 \mathrm{Mol}$ of lactate. The central enzyme of this pathway is represented by the fructose-6-phosphoketolase, of which the encoding gene is widely used as genetic marker for the genus Bifidobacterium [95].

In general, glucose and fructose can enter directly into the "bifid shunt" pathway, while other sugars are degraded by the intervention of additional glycosyl hydrolases, depending on the strategy of niche adaptation and carbon source availability [93,96-102].

According to the Cazy database classification (http:// afmb.cnrs-mrs.fr/CAZY/index. html) the glycosyl hydrolases that are most commonly found in bifidobacteria belong to the GH13 ( $\alpha$-glucosidase and sucrose phosphorylase), GH36 ( $\alpha$-galactosidase) and GH2/42 ( $\beta$-galactosidase). Representatives of the GH13 family are typically enzymes responsible for the degradation of substrates with $\alpha$-glucopyranose units, such as pullulan, glycogen, maltodextrin, starch, and amylopectin, and their presence has been pointed out as a characteristic feature of $B$. breve [103]. Members of the GH36 family frequently represent enzymes dedicated to the hydrolysis of $\alpha$-galacto-oligosaccharides present in soymilk and various plants (i.e., melibiose, raffinose, stachyose) [102,104].

Enzymes which fall into the $\beta$-galactosidase group generate galactose that enters the central carbon metabolism through the Leloir pathway, which is necessary for bacterial growth on (ga)lactose-containing host-derived substrates such as human milk oligosaccharides (HMO) and mucin.

\section{Carbohydrate degradation capabilities of Bifidobacterium species influence their presence and contribution to microbiota composition}

The dominance of bifidobacteria in the (breast-fed) infant gut microbiota has been attributed to the ability of certain bifidobacterial species to consume human milk oligosaccharides (HMOs). Recent fecal microbiota compositional analysis from 11 neonates established that Actinobacteria represented the dominant phyla at $88.5 \%$ with the Firmicutes represented at 11.1\% [105]. The most abundant classes in the infant fecal samples was Bifidobacteriales, being present at $80.6 \%$, while Lactobacillales and Clostridiales represented the second and third most abundant classes and being present at 7.2\% and $3.1 \%$, respectively. The dominant Bifidobacterium species detected in the infant fecal samples were B. longum and B. bifidum at $56.2 \%$ and $10.7 \%$, respectively [105], while it was noted that these two Bifidobacterium species were apparently absent in a study that analysed the Bifidobacterium composition of the adult gut microbiota [106]. The dominance of $B$. longum and B. bifidum in the infant gut microbiota is consistent with their ability to use host-derived oligosaccharides such as mucin and HMO. Mucin-type $O$-glycans are constituents of mucins, which are located in different mucosal sites of the body. The four main core glycan structures are made up of a combination of galactose, $N$-acetylglucosamine, $N$-acetylgalactosamine, fucose and sialic acid, linked through various glycosidic bonds [107]. HMOs are synthesized in the mammary gland and contain glucose, galactose, $N$-acetylglucosamine, fucose and sialic acid linked by at least 12 different glycosidic bonds [108]. The core of both mucin-type $\mathrm{O}$-glycans and HMOs is composed of the same building blocks, which can be connected together by various glycosidic links in order to assume a range of structures, whose degradation still involves a similar set of enzymes, among others $\beta$-hexosaminidases, $\beta$-galactosidases and $\alpha$-sialidases $[95,109]$. A case of differential host glycan utilization in bifidobacteria is represented by B. bifidum PRL2010 and B. longum subsp. infantis ATCC 15697, of which the former is able to utilize both mucin-type glycans and HMOs [109], while the latter is only capable of degrading HMO, suggesting that a (partially) divergent strategy of adaptation to the infant gut was applied in either of these bacteria [109]. While not all bifidobacterial species can utilize HMO directly, many can cross-feed on HMO degradation products that are liberated by the action of extracellular glycosyl-hydrolases. These degradation products/cross-feeding substrates may include sialic acid, fucose, lacto- $N$-tetraose (LnT) and lacto- $N$-biose and their consumption by other bifidobacterial species is likely to shape the particular composition of the infant microbiota. This nutrient-based crossfeeding or cooperative resource-sharing allows other bifidobacterial species that do not directly utilize HMO to establish themselves in the infant GIT, and supports the notion that the diet has a definitive impact on the gut microbiota composition. 
Previous genomic analyses have described how infant associated bifidobacterial species (e.g. B. bifidum and $B$. longum subsp. infantis) are genetically adapted to utilize host produced glycans such as mucins and HMO [110], while other bifidobacterial species including $B$. breve. B. longum subsp. longum and B. adolescentis are adapted to crossfeed on host derived glycans, while they also harbor a repertoire of enzymes dedicated to the metabolism of dietary plant-derived oligo- and polysaccharides. This diversity in carbohydrate utilization allows persistence of particular Bifidobacterium species in the microbiota irrespective of host age and host diet. This notion is exemplified by $B$. breve UCC2003 which, despite being a nursling stool isolate, has the capability to utilize several plant derived carbohydrates including starch, galactan and cellodextrins that would comprise part of the adult diet (Figure 2). In addition, B. breve strains can efficiently utilize LnT and sialic acid as energy sources and can crossfeed on HMO degradation products allowing this bifidobacterial species to establish as part of the breast fed infant microbiota despite not being capable of directly utilizing HMO (our unpublished results).

\section{Conclusion}

It is just over 10 years since the first Bifidobacterium genome sequence was published. Since then there has been an exponential increase in genome sequencing efforts with, in many instances, the goal of identifying the genes, and unravelling molecular mechanisms, associated with a specific probiotic attribute of a particular Bifidobacterium strain. Through comparative and functional genomics these efforts have unveiled the mode of action for particular probiotic attributes. The next decades of bifidobacterial research hold great promise and anticipation as additional novel representatives of the Bifidobacterium genus are expected to be isolated, while further insights into this intriguing group of bacteria, and the underlying mechanisms that explain how they interact with their human host and impart their probiotic effects will be unveiled.

\section{Competing interests}

The authors declare that they have no competing interests.

\section{Acknowledgements \\ The Alimentary Pharmabiotic Centre is a research centre funded by Science Foundation Ireland (SFI), through the Irish Government's National Development Plan. The authors and their work were supported by SFI (grant nos. 07/CE/B1368 and SFI/12/RC/2273) and a HRB postdoctoral fellowship (Grant no. PDTM/20011/9) awarded to MOCM. FB acknowledges financial assistance through an IRCSET postgraduate fellowship.}

\section{Declarations}

This article has been published as part of Microbial Cell Factories Volume 13 Supplement 1, 2014: Proceedings of the 11th International Symposium on Lactic Acid Bacteria. The full contents of the supplement are available online at http://www.microbialcellfactories.com/supplements/13/S1. Publication charges for this supplement were funded by the Stichting Symposium on Lactic Acid Bacteria. The articles have undergone the journal's standard peer review process for supplements. EJ is employed by Chr Hansen A/S, is a shareholder in Chr Hansen A/S; and has applied for patents relating to the content of an article which he did not edit but which forms part of this supplement. MK is an employee of Nizo. The other Supplement Editors declare that they have no competing interests.

\section{Authors' details}

${ }^{1}$ Alimentary Pharmabiotic Centre and School of Microbiology, National University of Ireland, Cork, Western Road, Cork, Ireland. ${ }^{2}$ Laboratory of Probiogenomics, Department of Life Sciences, University of Parma, Italy.

Published: 29 August 2014

\section{References}

1. Ventura M, Canchaya C, Tauch A, Chandra G, Fitzgerald GF, Chater KF, van Sinderen D: Genomics of Actinobacteria: tracing the evolutionary history of an ancient phylum. Microbiol Mol Biol Rev 2007, 71:495-548.

2. Berdy J: Bioactive microbial metabolites. J Antibiot (Tokyo) 2005, 58:1-26.

3. Procópio RE, Silva IR, Martins MK, Azevedo JL, Araújo JM: Antibiotics produced by Streptomyces. Braz J Infect Dis 2012, 16:466-471.

4. Turroni F, Peano C, Pass DA, Foroni E, Severgnini M, Claesson MJ, Kerr C, Hourihane J, Murray D, Fuligni F, Gueimonde M, Margolles A, De Bellis G, OToole PW, van Sinderen D, Marchesi JR, Ventura M: Diversity of Bifidobacteria within the Infant Gut Microbiota. PLoS One 2012, 7:e36957.

5. Kopecný J, Mrázek J, Killer J: The presence of bifidobacteria in social insects, fish and reptiles. Folia Microbiol (Praha) 2010, 55(4):336-339.

6. Vásquez A1, Forsgren E, Fries I, Paxton RJ, Flaberg E, Szekely L, Olofsson TC: Symbionts as major modulators of insect health: lactic acid bacteria and honeybees. PLoS One 2012, 7:e33188.

7. Tissier $\mathrm{H}$ : Recherchers sur la flora intestinale normale et pathologique du nourisson University of Paris, Paris, France; 1900.

8. Holzapfel WH, Haberer P, Geisen R, Björkroth J, Schillinger U: Taxonomy and important features of probiotic microorganisms in food and nutrition. Am J Clin Nutr 2001, 73365S-373S.

9. Ventura M, Canchaya C, Del Casale A, Dellaglio F, Neviani E, Fitzgerald GF, van Sinderen D: Analysis of bifidobacterial evolution using a multilocus approach. Int J Syst Evol Microbiol 2006, 56:2783-2792.

10. Kim MS, Roh SW, Bae JW: Bifidobacterium stercoris sp. nov., isolated from human faeces. Int J Syst Evol Microbiol 2010, 60:2823-2827.

11. Killer J, Kopecny J, Mrazek J, Koppova I, Havlik J, Benada O, Kott T: Bifidobacterium actinocoloniiforme sp. nov. and Bifidobacterium bohemicum sp. nov., from the bumblebee digestive tract. Int I Syst Evol Microbiol 2011, 61:1315-1321.

12. Endo A, Futagawa-Endo $Y$, Schumann $P$, Pukall $R$, Dicks LM: Bifidobacterium reuteri sp. nov., Bifidobacterium callitrichos sp. nov., Bifidobacterium saguini sp. nov., Bifidobacterium stellenboschense sp. nov. and Bifidobacterium biavatii sp. nov. isolated from faeces of common marmoset (Callithrix jacchus) and red-handed tamarin (Saguinus midas). Syst Appl Microbiol 2012, 35:92-97.

13. Tsuchida S, Takahashi S, Mbehang Nguema PP, Fujita S, Kitahara M, Yamagiwa J, Ngomanda A, Ohkuma M, Ushida K: Bifidobacterium moukalabense sp. nov. isolated from the faeces of wild west lowland gorilla (Gorilla gorilla gorilla) in Gabon. Int J Syst Evol Microbiol 2014, 64:449-55.

14. Zoetendal EG, Rajilic-Stojanovic M, de Vos WM: High-throughput diversity and functionality analysis of the gastrointestinal tract microbiota. Gut 2008, 57:1605-1615.

15. Scardovi TLD: Bifidobacterium animalis (Mitsuoka) comb. nov. and the "minimum" and "subtile" groups of new bifidobacteria found in sewage. Int J Syst Bacteriol 1974, 24:21-28.

16. Watanabe K, Makino H, Sasamoto M, Kudo Y, Fujimoto J, Demberel S: Bifidobacterium mongoliense sp. nov., from airag, a traditional fermented mare's milk product from Mongolia. Int J Syst Evol Microbiol 2009, 59:1535-1540.

17. Dong $X$, Xin $Y$, Jian W, Liu X, Ling D: Bifidobacterium thermacidophilum sp. nov., isolated from an anaerobic digester. Int J Syst Evol Microbiol 2000, 50:119-125.

18. Turroni F, van Sinderen D, Ventura M: Genomics and ecological overview of the genus Bifidobacterium. Int J Food Microbiol 2011, 149:37-44. 
19. Sela DA, Chapman J, Adeuya A, Kim JH, Chen F, Whitehead TR, Lapidus A, Rokhsar DS, Lebrilla CB, German JB, Price NP, Richardson PM, Mills DA: The genome sequence of Bifidobacterium longum subsp. infantis reveals adaptations for milk utilization within the infant microbiome. Proc Natl Acad Sci USA 2008, 105:18964-18969.

20. Kapatral V, Anderson I, Ivanova N, Reznik G, Los T, Lykidis A, Bhattacharyya A, Bartman A, Gardner W, Grechkin G, Zhu L, Vasieva O, Chu L, Kogan Y, Chaga O, Goltsman E, Bernal A, Larsen N, D'Souza M, Walunas T, Pusch G, Haselkorn R, Fonstein M, Kyrpides N, Overbeek R: Genome sequence and analysis of the oral bacterium Fusobacterium nucleatum strain ATCC 25586. J Bacteriol 2002, 184:2005-2018.

21. Ventura $M$, Turroni F, Zomer A, Foroni E, Giubellini V, Bottacini F, Canchaya C, Claesson MJ, He F, Mantzourani M, Mulas L, Ferrarini A, Gao B, Delledonne M, Henrissat B, Coutinho P, Oggioni M, Gupta RS, Zhang Z, Beighton D, Fitzgerald GF, OToole PW, van Sinderen D: The Bifidobacterium dentium Bd1 genome sequence reflects its genetic adaptation to the human oral cavity. PLOS Genet 2009, 5:e1000785.

22. Christensen BB, Atlung T, Hansen FG: DnaA boxes are important elements in setting the initiation mass of Escherichia coli. J Bacteriol 1999, 181:2683-2688.

23. McLean MJ, Wolfe KH, Devine KM: Base composition skews, replication orientation, and gene orientation in 12 prokaryote genomes. J Mol Evol 1998, 47:691-696.

24. Klaenhammer TR, Barrangou R, Buck BL, Azcarate-Peril MA, Altermann E: Genomic features of lactic acid bacteria effecting bioprocessing and health. FEMS Microbiol Rev 2005, 29:393-409.

25. Hols P, Hancy F, Fontaine L, Grossiord B, Prozzi D, Leblond-Bourget N, Decaris B, Bolotin A, Delorme C, Dusko Ehrlich S, Guédon E, Monnet V, Renault $P$, Kleerebezem M: New insights in the molecular biology and physiology of Streptococcus thermophilus revealed by comparative genomics. FEMS Microbiol Rev 2005, 29:435-463.

26. Makarova K, Slesarev A, Wolf Y, Sorokin A, Mirkin B, Koonin E, Pavlov A, Pavlova N, Karamychev V, Polouchine N, Shakhova V, Grigoriev I, Lou Y, Rohksar D, Lucas S, Huang K, Goodstein DM, Hawkins T, Plengvidhya V, Welker D, Hughes J, Goh Y, Benson A, Baldwin K, Lee JH, Díaz-Muñiz I, Dosti B, Smeianov V, Wechter W, Barabote R, Lorca G, Altermann E, Barrangou R, Ganesan B, Xie Y, Rawsthorne H, Tamir D, Parker C, Breidt F, Broadbent J, Hutkins R, O'Sullivan D, Steele J, Unlu G, Saier M, Klaenhammer T, Richardson P, Kozyavkin S, Weimer B, Mills D: Comparative genomics of the lactic acid bacteria. Proc Natl Acad Sci USA 2006, 103:15611-15616.

27. Bottacini F, Medini D, Pavesi A, Turroni F, Foroni E, Riley D, Giubellini V, Tettelin $H$, van Sinderen D, Ventura M: Comparative genomics of the genus Bifidobacterium. Microbiology 2010, 156:3243-3254.

28. Bottacini F, O' Connell Motherway M, Kuczynski J, O' Connell KJ, Serafini F, Duranti S, Milani C, Turroni F, Lugli G, Zomer A, Zhurina D, Riedel CU, Ventura $M$, van Sinderen D: Comparative genomics of the Bifidobacterium breve taxon. BMC Genomics 2014.

29. Lee JH, O'Sullivan DJ: Genomic insights into bifidobacteria. Microbiol Mol Biol Rev 2010, 74:378-416.

30. Ventura M, Lee JH, Canchaya C, Zink R, Leahy S, Moreno-Munoz JA, O'Connell-Motherway M, Higgins D, Fitzgerald GF, O'Sullivan DJ, van Sinderen D: Prophage-like elements in bifidobacteria: insights from genomics, transcription, integration, distribution, and phylogenetic analysis. Appl Environ Microbiol 2005, 71:8692-8705.

31. Sgorbati B, Smiley MB, Sozzi T: Plasmids and phages in Bifidobacterium longum. Microbiologica 1983, 6:169-173.

32. Ventura M, Turroni F, Lima-Mendez G, Foroni E, Zomer A, Duranti S, Giubellini V, Bottacini F, Horvath P, Barrangou R, Sela DA, Mills DA, van Sinderen D: Comparative analyses of prophage-like elements present in bifidobacterial genomes. Appl Environ Microbiol 2009, 75:6929-6936.

33. Canchaya C, Fournous G, Chibani-Chennoufi S, Dillmann ML, Brussow H: Phage as agents of lateral gene transfer. Curr Opin Microbiol 2003, 6:417-424.

34. Murray NE: Immigration control of DNA in bacteria: self versus non-self. Microbiology 2002, 148:3-20.

35. Roberts RJ, Belfort M, Bestor T, Bhagwat AS, Bickle TA, Bitinaite J, Blumenthal RM, Degtyarev SKh, Dryden DT, Dybvig K, Firman K, Gromova ES, Gumport Rl, Halford SE, Hattman S, Heitman J, Hornby DP, Janulaitis A, Jeltsch A, Josephsen J, Kiss A, Klaenhammer TR, Kobayashi I, Kong $\mathrm{H}$, Krüger DH, Lacks S, Marinus MG, Miyahara M, Morgan RD,
Murray NE, Nagaraja V, Piekarowicz A, Pingoud A, Raleigh E, Rao DN, Reich N, Repin VE, Selker EU, Shaw PC, Stein DC, Stoddard BL, Szybalski W, Trautner TA, Van Etten JL, Vitor JM, Wilson GG, Xu SY: A nomenclature for restriction enzymes, DNA methyltransferases, homing endonucleases and their genes. Nucleic Acids Res 2003, 31:1805-12.

36. Khosaka T, Sakurai T, Takahashi H, Saito H: A new site-specific endonuclease Bbel from Bifidobacterium breve. Gene 1982, 17:117-122.

37. Khosaka T, Kiwaki M, Rak B: Two site-specific endonucleases BinSI and BinSII from Bifidobacterium infantis. FEBS Lett 1983, 163:170-174.

38. Khosaka T, Kiwaki M: Binl: a new site-specific endonuclease from Bifidobacterium infantis. Gene 1984, 31:251-255.

39. Skrypina NA, Kramarov VM, Liannaia AM, Smolianinov W: Restriction endonucleases from bifidobacteria. Mol Gen Mikrobiol Virusol 1988, 5:15-16.

40. Hartke A, Benachour A, Bouibonnes P, Auffray $Y$ : Characterisation of a complex restriction/modification system detected in a Bifidobacterium longum strain. Appl Microbiol Biotechnol 1996, 45:132-136.

41. Kim JY, Wang Y, Park MS, Ji GE: Improvement of transformation efficiency through in vitro methylation and Sacll site mutation of plasmid vector in Bifidobacterium longum MG1. J Microbiol Biotechnol 2010, 20:1022-1026.

42. Yasui K, Kano Y, Tanaka K, Watanabe K, Shimizu-Kadota M, Yoshikawa H, Suzuki T: Improvement of bacterial transformation efficiency using plasmid artificial modification. Nucleic Acids Res 2009, 37(1):e3.

43. Ruiz L, Motherway MO, Lanigan N, van Sinderen D: Transposon mutagenesis in Bifidobacterium breve: construction and characterization of a Tn5 transposon mutant library for Bifidobacterium breve UCC2003. PLoS One 2013, 8(5):e64699.

44. O'Connell Motherway M, O'Driscoll J, Fitzgerald GF, Van Sinderen D: Overcoming the restriction barrier to plasmid transformation and targeted mutagenesis in Bifidobacterium breve UCC2003. Microb Biotechnol 2009, 2(3):321-32.

45. O'Connell KJ, Motherway MO, Hennessey AA, Brodhun F, Ross RP, Feussner I, Stanton C, Fitzgerald GF, van Sinderen D: Identification and characterization of an oleate hydratase-encoding gene from Bifidobacterium breve. Bioengineered 2013, 4:313-21.

46. Hottes AK, Freddolino PL, Khare A, Donnell ZN, Liu JC, Tavazoie S: Bacterial adaptation through loss of function. PLoS Genet 2013, 9(7):e1003617.

47. Bottacini F, Milani C, Turroni F, Sánchez B, Foroni E, Duranti S, Serafini F, Viappiani A, Strati F, Ferrarini A, Delledonne M, Henrissat B, Coutinho P, Fitzgerald GF, Margolles A, van Sinderen D, Ventura M: Bifidobacterium asteroides PRL2011 genome analysis reveals clues for colonization of the insect gut. PLoS One 2012, 7:e44229.

48. O'Connell Motherway M, Zomer A, Leahy SC, Reunanen J, Bottacini F, Claesson MJ, O'Brien F, Flynn K, Casey PG, Munoz JA, Kearney B, Houston AM, O'Mahony C, Higgins DG, Shanahan F, Palva A, de Vos WM, Fitzgerald GF, Ventura M, OToole PW, van Sinderen D: Functional genome analysis of Bifidobacterium breve UCC2003 reveals type IVb tight adherence (Tad) pili as an essential and conserved host-colonization factor. Proc Natl Acad Sci USA 2011, 108:11217-11222.

49. Ruiz L, O'Connell-Motherway M, Zomer A, de los Reyes-Gavilán CG, Margolles A, van Sinderen D: A bile-inducible membrane protein mediates bifidobacterial bile resistance. Microb Biotechnol 2012, 5:523-535

50. Ruiz L, Margolles A, Sánchez B: Bile resistance mechanisms in Lactobacillus and Bifidobacterium. Front Microbiol 2013, 4:396.

51. Alvarez-Martin P, Fernández M, O'Connell-Motherway M, O'Connell KJ Sauvageot N, Fitzgerald GF, MacSharry J, Zomer A, van Sinderen D: A conserved two-component signal transduction system controls the response to phosphate starvation in Bifidobacterium breve UCC2003. Appl Environ Microbiol 2012, 78:5258-69.

52. Alvarez-Martin $\mathrm{P}, \mathrm{O}^{\prime}$ Connell Motherway $M$, Turroni F, Foroni E, Ventura M, van Sinderen D: A two-component regulatory system controls autoregulated serpin expression in Bifidobacterium breve UCC2003. Appl Environ Microbiol 2012, 78:7032-7041.

53. Turroni F, Foroni E, O'Connell Motherway M, Bottacini F, Giubellini V Zomer A, Ferrarini A, Delledonne M, Zhang Z, van Sinderen D, Ventura M: Characterization of the serpin-encoding gene of Bifidobacterium breve 210B. Appl Environ Microbiol 2010, 76:3206-3219.

54. De Dea Lindner J, Canchaya C, Zhang Z, Neviani E, Fitzgerald GF, van Sinderen D, Ventura M: Exploiting Bifidobacterium genomes: the molecular basis of stress response. Int J Food Microbiol 2007, 120:13-24. 
55. Zomer A, Fernandez M, Kearney B, Fitzgerald GF, Ventura M, van Sinderen D: An interactive regulatory network controls stress response in Bifidobacterium breve UCC2003. J Bacteriol 2009, 191:7039-7049.

56. Price CE, Reid SJ, Driessen AJ, Abratt VR: The Bifidobacterium longum NCIMB 702259T ctr gene codes for a novel cholate transporter. Appl Environ Microbiol 2006, 72:923-6.

57. Gueimonde M, Garrigues C, van Sinderen D, de los Reyes-GavilánC G, Margolles A: Bile-inducible efflux transporter from Bifidobacterium longum NCC2705, conferring bile resistance. Appl Environ Microbiol 2009 75:3153-3160.

58. Fanning S, Hall LJ, Cronin M, Zomer A, MacSharry J, Goulding D, Motherway MO, Shanahan F, Nally K, Dougan G, van Sinderen D: Bifidobacterial surface-exopolysaccharide facilitates commensal-host interaction through immune modulation and pathogen protection. Proc Natl Acad Sci USA 2012, 109:2108-2113.

59. Turroni F, Serafini F, Foroni E, Duranti S, O'Connell Motherway M, Taverniti V, Mangifesta M, Milani C, Viappiani A, Roversi T, Sánchez B, Santoni A, Gioiosa L, Ferrarini A, Delledonne M, Margolles A, Piazza L, Palanza P, Bolchi A, Guglielmetti S, van Sinderen D, Ventura M: Role of sortase-dependent pili of Bifidobacterium bifidum PRL2010 in modulating bacterium-host interactions. Proc Natl Acad Sci USA 2013, 110:11151-11156.

60. Perez PF, Minnaard Y, Disalvo EA, De Antoni GL: Surface properties of bifidobacterial strains of human origin. Appl Environ Microbiol 1998, 64:21-26.

61. Ruas-Madiedo P, Gueimonde M, Arigoni F, de los Reyes-Gavilan CG, Margolles A: Bile affects the synthesis of exopolysaccharides by Bifidobacterium animalis. Appl Environ Microbiol 2009, 75:1204-1207.

62. Schell MA, Karmirantzou M, Snel B, Vilanova D, Berger B, Pessi G, Zwahlen MC, Desiere F, Bork P, Delley M, Pridmore RD, Arigoni F: The genome sequence of Bifidobacterium longum reflects its adaptation to the human gastrointestinal tract. Proc Natl Acad Sci USA 2002, 99:14422-14427.

63. Klijn A, Mercenier A, Arigoni F: Lessons from the genomes of bifidobacteria. FEMS Microbiol Rev 2005, 29:491-509.

64. Foroni $E$, Serafini F, Amidani D, Turroni F, He F, Bottacini F, O'Connell Motherway M, Viappiani A, Zhang Z, Rivetti C, van Sinderen D, Ventura M: Genetic analysis and morphological identification of pilus-like structures in members of the genus Bifidobacterium. Microb Cell Fact 2011, 10:S16.

65. Merino S, Tomas JM: Bacterial Capsules and Evasion of Immune Responses John Wiley \& Sons, Ltd, NJ; 2010

66. Alp G, Aslim B: Relationship between the resistance to bile salts and low $\mathrm{pH}$ with exopolysaccharide (EPS) production of Bifidobacterium spp. isolated from infants feces and breast milk. Anaerobe 2010, 16:101-105.

67. Fanning S, Hall LJ, van Sinderen D: Bifidobacterium breve UCC2003 surface exopolysaccharide production is a beneficial trait mediating commensalhost interaction through immune modulation and pathogen protection. Gut Microbes 2012, 3:420-425

68. Chapot-Chartier MP, Vinogradov E, Sadovskaya I, Andre G, Mistou MY, TrieuCuot P, Furlan S, Bidnenko E, Courtin P, Péchoux C, Hols P, Dufrêne YF, Kulakauskas S: Cell surface of Lactococcus lactis is covered by a protective polysaccharide pellicle. J Biol Chem 2010, 285:10464-10471.

69. Coyne MJ, Weinacht KG, Krinos CM, Comstock LE: Mpi recombinase globally modulates the surface architecture of a human commensal bacterium. Proc Natl Acad Sci USA 2003, 100:10446-10451.

70. Hidalgo-Cantabrana C, Sanchez B, Milani C, Ventura M, Margolles A, RuasMadiedo P: Exopolysaccharide biosynthesis in Bifidobacterium spp.: biological functions and a genomic overview. Appl Environ Microbiol 2014, 80:9-18

71. Filloux A: A variety of bacterial pili involved in horizontal gene transfer. J Bacteriol 2010, 192:3243-3245.

72. Scott JR, Zahner D: Pili with strong attachments: Gram-positive bacteria do it differently. Mol Microbiol 2006, 62:320-330.

73. Kachlany SC, Planet PJ, Desalle R, Fine DH, Figurski DH, Kaplan JB: flp-1, the first representative of a new pilin gene subfamily, is required for nonspecific adherence of Actinobacillus actinomycetemcomitans. Mol Microbiol 2001, 40:542-554

74. Schreiner HC, Sinatra K, Kaplan JB, Furgang D, Kachlany SC, Planet PJ, Perez BA, Figurski DH, Fine DH: Tight-adherence genes of Actinobacillus actinomycetemcomitans are required for virulence in a rat model. Proc Natl Acad Sci USA 2003, 100:7295-7300.
75. Kachlany SC, Planet PJ, DeSalle R, Fine DH, Figurski DH: Genes for tight adherence of Actinobacillus actinomycetemcomitans: from plaque to plague to pond scum. Trends Microbiol 2001, 9:429-437.

76. Planet PJ, Kachlany SC, Fine DH, DeSalle R, Figurski DH: The Widespread Colonization Island of Actinobacillus actinomycetemcomitans. Nat Genet 2003, 34:193-198.

77. Kankainen M, Paulin L, Tynkkynen S, von Ossowski I, Reunanen J, Partanen P, Satokari R, Vesterlund S, Hendrickx AP, Lebeer S, De Keersmaecker SC, Vanderleyden J, Hämäläinen T, Laukkanen S, Salovuori N, Ritari J, Alatalo E, Korpela R, Mattila-Sandholm T, Lassig A, Hatakka K, Kinnunen KT, Karjalainen H, Saxelin M, Laakso K, Surakka A, Palva A, Salusjärvi T, Auvinen P, de Vos WM: Comparative genomic analysis of Lactobacillus rhamnosus GG reveals pili containing a human- mucus binding protein. Proc Natl Acad Sci USA 2009, 106:17193-17198.

78. Tripathi P, Beaussart A, Alsteens D, Dupres V, Claes I, von Ossowski I, de Vos WM, Palva A, Lebeer S, Vanderleyden J, Dufrêne YF: Adhesion and nanomechanics of pili from the probiotic Lactobacillus rhamnosus GG. ACS Nano 2013, 7:3685-3697.

79. Galdeano CM, de Moreno de LeBlanc A, Vinderola G, Bonet ME, Perdigon G: Proposed model: mechanisms of immunomodulation induced by probiotic bacteria. Clinical and vaccine immunology 2007, 14:485-492.

80. Xavier KB, Bassler BL: LuxS quorum sensing: more than just a numbers game. Curr Opin Microbiol 2003, 6:191-197.

81. Choi J, Shin D, Kim M, Park J, Lim S, Ryu S: LsrR-mediated quorum sensing controls invasiveness of Salmonella typhimurium by regulating SPI-1 and flagella genes. PLOS One 2012, 7(5):e37059.

82. Kim SY, Lee SE, Kim YR, Kim CM, Ryu PY, Choy HE, Chung SS, Rhee JH: Regulation of Vibrio vulnificus virulence by the LuXS quorum-sensing system. Mol Microbiol 2003, 48:1647-1664.

83. Buck BL, Azcarate-Peril MA, Klaenhammer TR: Role of autoinducer-2 on the adhesion ability of Lactobacillus acidophilus. J Appl Microbiol 2009, 107:269-279.

84. Lebeer S, Claes IJ, Verhoeven TL, Shen C, Lambrichts I, Ceuppens JL, Vanderleyden J, De Keersmaecker SC: Impact of luxS and suppressor mutations on the gastrointestinal transit of Lactobacillus rhamnosus GG. Appl Environ Microbiol 2008, 74:4711-4718.

85. Lebeer S, De Keersmaecker SC, Verhoeven TL, Fadda AA, Marchal K, and Vanderleyden J: Functional analysis of luxS in the probiotic strain Lactobacillus rhamnosus GG reveals a central metabolic role important for growth and biofilm formation. J Bacterio/ 2007, , 189: 860-871.

86. Wilson CM, Aggio RB, OToole PW, Villas-Boas S, Tannock GW: Transcriptional and metabolomic consequences of LuxS inactivation reveal a metabolic rather than quorum-sensing role for LuxS in Lactobacillus reuteri 100-23. J Bacteriol 2012, 194:1743-1746.

87. Carey CM, Kostrzynska M: Lactic acid bacteria and bifidobacteria attenuate the proinflammatory response in intestinal epithelial cells induced by Salmonella enterica serovar Typhimurium. Can J Microbiol 2013, 59(1):9-17

88. Scott KP, Gratz SW, Sheridan PO, Flint HJ, Duncan SH: The influence of diet on the gut microbiota. Pharmacol Res 2013, 69:52-60.

89. Fukuda S, Toh H, Hase K, Oshima K, Nakanishi Y, Yoshimura K, Tobe T, Clarke JM, Topping DL, Suzuki T, Taylor TD, Itoh K, Kikuchi J, Morita H, Hattori M, Ohno H: Bifidobacteria can protect from enteropathogenic infection through production of acetate. Nature 2011, 469:543-547.

90. De Vuyst L, Leroy F: Cross-feeding between bifidobacteria and butyrateproducing colon bacteria explains bifdobacterial competitiveness, butyrate production, and gas production. Int J Food Microbiol 2011, 149:73-80.

91. Leonel AJ, Alvarez-Leite Jl: Butyrate: implications for intestinal function. Curr Opin Clin Nutr Metab Care 2012, 15:474-479.

92. Coakley M, Ross RP, Nordgren M, Fitzgerald G, Devery R, Stanton C Conjugated linoleic acid biosynthesis by human-derived Bifidobacterium species. J Appl Microbiol 2003, 94:138-145.

93. Russell DA, Ross RP, Fitzgerald GF, Stanton C: Metabolic activities and probiotic potential of bifidobacteria. Int J Food Microbiol 2011, 149:88-105.

94. Pokusaeva K, Fitzgerald GF, van Sinderen D: Carbohydrate metabolism in bifidobacteria. Genes Nutr 2011, 6:285-306.

95. de Vries W, Stouthamer AH: Pathway of glucose fermentation in relation to the taxonomy of bifidobacteria. J Bacteriol 1967, 93:574-576.

96. Kim JH, An HJ, Garrido D, German JB, Lebrilla CB, Mills DA: Proteomic analysis of Bifidobacterium longum subsp. infantis reveals the metabolic 
insight on consumption of prebiotics and host glycans. PLoS One 2013, 8: e57535.

97. Sela DA, Mills DA: Nursing our microbiota: molecular linkages between bifidobacteria and milk oligosaccharides. Trends Microbiol 2010, 18:298-307.

98. Turroni F, Milani C, van Sinderen D, Ventura M: Genetic strategies for mucin metabolism in Bifidobacterium bifidum PRL2010: an example of possible human-microbe co-evolution. Gut Microbes 2011, 2:183-189.

99. Pokusaeva K, O'Connell-Motherway M, Zomer A, Fitzgerald GF, van Sinderen D: Characterization of two novel alpha-glucosidases from Bifidobacterium breve UCC2003. Appl Environ Microbiol 2009, 75:1135-1143.

100. Pokusaeva K, O'Connell-Motherway M, Zomer A, Macsharry J, Fitzgerald GF, van Sinderen D: Cellodextrin utilization by Bifidobacterium breve UCC2003. Appl Environ Microbiol 2011, 77:1681-1690.

101. O'Connell Motherway M, Fitzgerald GF, Neirynck S, Ryan S, Steidler L, van Sinderen D: Characterization of ApuB, an extracellular type II amylopullulanase from Bifidobacterium breve UCC2003. Appl Environ Microbiol 2008, 74:6271-6279.

102. O'Connell Motherway M, Kinsella M, Fitzgerald GF, van Sinderen D: Transcriptional and functional characterization of genetic elements involved in galacto-oligosaccharide utilization by Bifidobacterium breve UCC2003. Microb Biotechnol 2013, 6:67-79.

103. Ryan SM, Fitzgerald GF, van Sinderen D: Screening for and identification of starch-, amylopectin-, and pullulan-degrading activities in bifidobacterial strains. Appl Environ Microbiol 2006, 72:5289-5296.

104. Goulas T, Goulas A, Tzortzis G, Gibson GR: A novel alpha-galactosidase from Bifidobacterium bifidum with transgalactosylating properties: gene molecular cloning and heterologous expression. Appl Microbiol Biotechnol 2009, 82:471-477.

105. Turroni F, Peano C, Pass DA, Foroni E, Severgnini M, Claesson MJ, Kerr C, Hourihane J, Murray D, Fuligni F, Gueimonde M, Margolles A, De Bellis G, OToole PW, van Sinderen D, Marchesi JR, Ventura M: Diversity of bifidobacteria within the infant gut microbiota. PLoS One 2012, 7:e36957.

106. Turroni F, Marchesi JR, Foroni E, Gueimonde M, Shanahan F, Margolles A, van Sinderen D, Ventura M: Microbiomic analysis of the bifidobacterial population in the human distal gut. ISME J 2009, 3:745-51.

107. Brockhausen I, Schachter H, Stanley P: O-GalNAc Glycans. In Essentials of Glycobiology.. 2 edition. Cold Spring Harbor (NY); Varki A, Cummings RD, Esko JD, Freeze HH, Stanley P, Bertozzi CR, Hart GW, Etzler ME 2009:; Chapter 9 .

108. Kunz C, Rudloff S, Baier W, Klein N, Strobel S: Oligosaccharides in human milk: structural, functional, and metabolic aspects. Annu Rev Nutr 2000, 20:699-722.

109. Turroni F, Bottacini F, Foroni E, Mulder I, Kim JH, Zomer A, Sánchez B, Bidossi A, Ferrarini A, Giubellini V, Delledonne M, Henrissat B, Coutinho P, Oggioni M, Fitzgerald GF, Mills D, Margolles A, Kelly D, van Sinderen D, Ventura M: Genome analysis of Bifidobacterium bifidum PRL2010 reveals metabolic pathways for host-derived glycan foraging. Proc Natl Acad SCi USA 2010, 107:19514-19519.

110. Sela DA, Mills DA: Nursing our microbiota: molecular linkages between bifidobacteria and milk oligosaccharides. Trends Microbiol 2010, 18:298-307.

doi:10.1186/1475-2859-13-S1-S4

Cite this article as: Bottacini et al:: Diversity, ecology and intestinal function of bifidobacteria. Microbial Cell Factories 2014 13(Suppl 1):S4.

\section{Submit your next manuscript to BioMed Central and take full advantage of:}

- Convenient online submission

- Thorough peer review

- No space constraints or color figure charges

- Immediate publication on acceptance

- Inclusion in PubMed, CAS, Scopus and Google Scholar

- Research which is freely available for redistribution

Submit your manuscript at www.biomedcentral.com/submit
Biomed Central 